\title{
Reaaliaikainen lehmien jalkaterveyden seuranta
}

Matti Pastell $^{1)}$, Mikko Hautala ${ }^{1)}$, Minna Kujala ${ }^{2)}$, Väinö Poikalainen ${ }^{3)}$, Jaan Praks ${ }^{3)}$, Imbi Veermäe ${ }^{3)}$ ja Jukka Ahokas ${ }^{1)}$

${ }^{1)}$ Agroteknologian laitos, PL 28 (Koetilantie 3) 00014, Helsingin Yliopisto. matti.pastell@ helsinki.fi

${ }^{2)}$ Saaren yksikkö, Pohjoinen pikatie 800,04920 Saarentaus.minna.j.kujala@helsinki.fi

${ }^{3}$ Estonian Agricultural University, Kreutzwaldi 64, 51014 Tartu, Estonia.rahko@eau.ee

\section{Tiivistelmä}

Teknologinen kehitys on mahdollistanut korkean automaatiotason myös karjataloudessa ja automaattilypsy on yleistynyt 2000-luvulla. Lypsyrobotti tarjoaa erinomaisen mahdollisuuden lehmien jatkuvaan automaattiseen seurantaan. Mittaamalla voidaan saada eläimen terveydentilasta selville sellaisiakin asioita joita ei voida silmämääräisesti havaita.

Ontuminen on kolmanneksi suurin lypsykarjan terveysongelma maailmassa. Se aiheuttaa tiloille kustannuksia hoidon ja menetetyn tuotoksen vuoksi sekä aiheuttaa lehmille kipua. Lypsylehmien ontumisesta $90 \%$ johtuu sorkkasairauksista. Sairauksien aiheuttaman haitan minimoinnissa tärkeintä on sairauden nopea havaitseminen ja välittömästi aloitettu hoito. Teknologisia keinoja ontumisen havaitsemiseen on käytössä vain vähän.

Helsingin yliopiston Agroteknologian laitoksella kehitettiin yhteistyössä Tarton maatalousyliopiston kanssa nelivaakajärjestelmä lehmien jalkavikojen automaattista seurantaa varten. Vaa'an avulla punnitaan lehmän jokaisen jalan paino erikseen lypsyn aikana. Järjestelmä koostuu neljästä leikkausvoima-anturista joiden päälle on asennettu vaakasillat, vahvistimesta ja tietokoneesta sekä seurantaohjelmistosta. Vaaka on asennettu Helsingin yliopiston opetus ja tutkimustilan Suitian toisen lypsyrobotin lattiaan.

Mittauksen kulkua ohjataan navetassa sijaitsevan tietokoneen ja tutkimuksessa kehitetyn ohjelmiston avulla. Tieto robotin toiminnasta ja siellä olevasta lehmästä saadaan robotin tietokoneelta DeLavalilta saadun apuohjelman avulla. Ohjelma aloittaa mittauksen lypsyn alkaessa ja lopettaa sen kun lypsy loppuu. Lypsyn päätyttyä ohjelma laskee jokaisen jalan keskipainon, jalkapainojen keskihajonnan, potkut ja jalannostot lypsyn aikana sekä lehmän kokonaispainon. Tiedot tallennetaan tietokantaan lehmäkohtaisesti. Ohjelmaan on myös lisätty jalkavikojen etsimisehto. Ohjelma vertaa jokaisen lypsyn päätyttyä lehmän jalkapainoja viiden edellisen päivän jalkapainoihin.

Järjestelmällä kerättiin punnitustuloksia 71 lehmästä yli 10000 kappaletta. Lehmien jalkaterveys on tarkastettu noin kuukauden välein ja tutkimuksen aikana on löytynyt jalkavikoja aikana yhteensä 12. Näistä 11 kappaletta havaittiin myös vaakajärjestelmällä. Järjestelmällä havaitut jalkaviat ilmenivät kipeän jalan keventämisenä ja pahimmat ontumistapaukset myös jalan jatkuvana nosteluna. Lehmien erilainen käyttäytyminen vaikeuttaa yhteisten vian etsintäkriteerien löytämistä. Selvimmin jalan kipeytyminen näkyy terveenä jatkuvasti tasaisesti seisovalla lehmällä, mutta levottoman lehmän sorkkasairaus ei erotu yhtä helposti normaalista punnitusten välisestä hajonnasta.

Lehmän jalkapainojen yksilöllisellä seurannalla pystytään seuraamaan eläimen jalkaterveyttä. Nelivaakajärjestelmä tarjoaa mahdollisuuden automaattiseen terveyden seurantaan tilatasolla. Järjestelmää ohjaava ohjelma antaa automaattisia hälytyksiä mahdollisista ongelmista.

\section{Asiasanat}

Lypsykarja, jalkaterveys, hyvinvoinnin mittaaminen, vaakajärjestelmä. 


\section{Johdanto}

Yksikkökoon kasvaessa eläinten hoitajille jää yhä vähemmän aikaa eläinten hyvinvoinnin tarkkailuun. Samaan aikaan maataloudessa lisääntynyt automaatio tarjoaa mahdollisuuden seurata eläinten käyttäytymistä ja fysiologista tilaa päivittäin esimerkiksi lypsyrobotilla tai ruokinta-automaatilla.

Hyvinvointia mittaamalla saadaan eläimestä selville myös sellaisia asioita, joita ei kokenutkaan tarkkailija pysty silmämääräisesti havaitsemaan. Luotettava mittaus- ja seurantajärjestelmä vähentää eläinten hoitajan työtaakkaa. Tuotantoeläimen hyvinvointi vaikuttaa myös tuotokseen ja sitä kautta taloudelliseen tulokseen. Automaattisten valvontajärjestelmillä avulla pystytään parantamaan tuotannon tehokkuutta ja laadun valvontaa (Frost ym. 1997).

Erilaiset jalkaviat ovat nykyisin hyvin yleisiä lypsykarjoissa. Ne aiheuttavat lehmille kipua ja tilalle suoria sekä epäsuoria kustannuksia (Klaas ym. 2003, Juarez ym. 2003). Epäsuorat kustannukset aiheutuvat lehmien heikentyneestä hedelmällisyydestä, kunnon heikkenemisestä ja tuotoksen laskusta. Noin $90 \%$ lehmien ontumisesta johtuu erilaisista sorkkasairauksista ja $80 \%$ niistä esiintyy takajaloissa (Vermunt 2004). Hillerton ym. (2004) toteavat jalkaterveyden vaativan automaattilypsyssä erityistä huomiota etenkin, jos automaattilypsyyn siirtymisen seurauksena luovutaan karjan laiduntamisesta.

Lypsylehmien tunnistaminen niiden kaulassa olevan transponderin perusteella mahdollistaa eläinten monipuolisen seurannan. Lypsyrobotti ja ruokintakioskit tallentavat jo nyt hyvin yksityiskohtaista tietoa lehmien tuotoksesta ja käyttäytymisestä. Tallennetun tiedon perusteella karjanhoitaja voi seurata lehmän toimintoja ja terveydentilaa. Esimerkiksi lehmän lypsykäyttäytyminen ja syödyn rehun määrä kertovat paljon sen aktiivisuudesta. Lypsyrobotti myös ilmoittaa käyttäjälle ovatko lehmät käyneet lypsyllä normaalisti ja onko maidon laadussa poikkeamia. Reaaliaikainen sorkkaterveyden seurantajärjestelmä mahdollistaa myös jalkavikojen ja sorkkasairauksien automaattisen seurannan.

Tutkimuksen tavoitteena oli selvittää pystytäänkö lypsykarjan jalkaviat havaitsemaan jatkuvalla reaaliaikaisella jalkapainojen seurannalla. Analysoitavia tietoja olivat sorkkakohtaiset painot ja niiden tilastolliset tunnusluvut sekä jalan nostojen määrä lypsyn aikana. Tutkimuksessa etsittiin vaakatietojen ja eläinlääkäriltä saatujen tietojen perusteella ontuvan lehmän kriteerit.

\section{Aineisto ja menetelmät}

Nelivaakajärjestelmän avulla voidaan punnita lehmän jokaisen jalan paino erikseen lypsyn aikana. Tutkimuksessa seurattiin jalkapainojen muutoksia täysin automatisoidulla mittauksella. Lehmien jalkapainot jokaisen lypsyn ajalta tallentuivat tekstitiedostoon mittaustietokoneen kovalevylle.

Järjestelmä koostuu neljästä leikkausvoima-anturista joiden päälle on asennettu vaakasillat, vahvistimesta ja tietokoneesta sekä seurantaohjelmistosta (Pastell ym. 2005, Takko 2004).Vaaka on asennettu Helsingin yliopiston opetus ja tutkimustilan Suitian toisen lypsyrobotin lattiaan. Järjestelmä on otettu käyttöön loppuvuodesta 2003, jonka jälkeen sitä on jatkuvasti kehitetty. Jokaisen neljän vaaka-anturin kapasiteetti on $500 \mathrm{~kg}$, mutta siitä huolimatta järjestelmän kestävyys on muodostunut ongelmaksi ja antureiden kiinnityksen lisäksi vaakaelementtejä on jouduttu vahvistamaan erityisellä pantarakenteella. Vahvistuksesta huolimatta antureiden kiinnityksiä on jouduttu korjaamaan ajoittain. Takana sijaitsevien levyjen koko on 445 x $390 \mathrm{~mm}$ ja etulevyt ovat kooltaan 335 x $335 \mathrm{~mm}$ ja 310 x $310 \mathrm{~mm}$ (Kuva 1). Etulevyt ovat takalevyjä pienemmät, koska lehmien takajalkojen paikka lypsyn aikana vaihtelee etujalkoja enemmän. Robotin toimintaa ja lehmien käytöstä seuraamaan on lisäksi asennettu 3 videokameraa. 


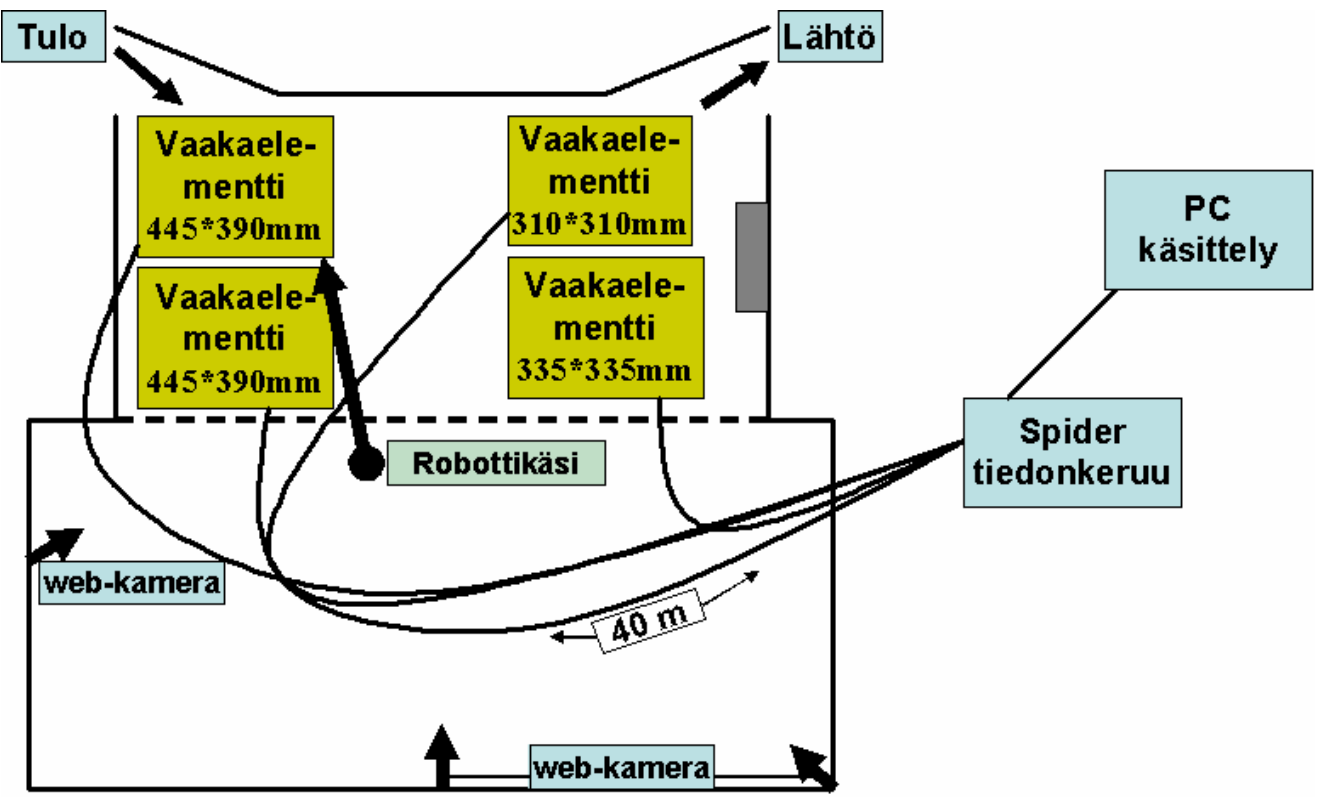

Kuva 1. Suitian nelivaakajärjestelmän vaakojen ja kameroiden sijoitus.

Mittauksen kulkua ohjataan navetassa sijaitsevan tietokoneen ja tutkimuksessa kehitetyn ohjelmiston avulla. Tieto robotin toiminnasta ja siellä olevasta lehmästä saadaan robotin tietokoneelta DeLavalilta saadun apuohjelman avulla. Ohjelma aloittaa mittauksen lypsyn alkaessa ja lopettaa sen kun lypsy loppuu. Lypsyn päätyttyä ohjelma laskee jokaisen jalan keskipainon, kokonaispainon, painojen keskihajonnan ja potkut lypsyn aikana. Yksi potku laskettiin, kun lehmän jonkun jalan paino kävi alle 20 kg:n. Tämän vuoksi lasketut potkut kuvaavat sekä potkimista että lehmän jalan nostelua (Kuva 2).

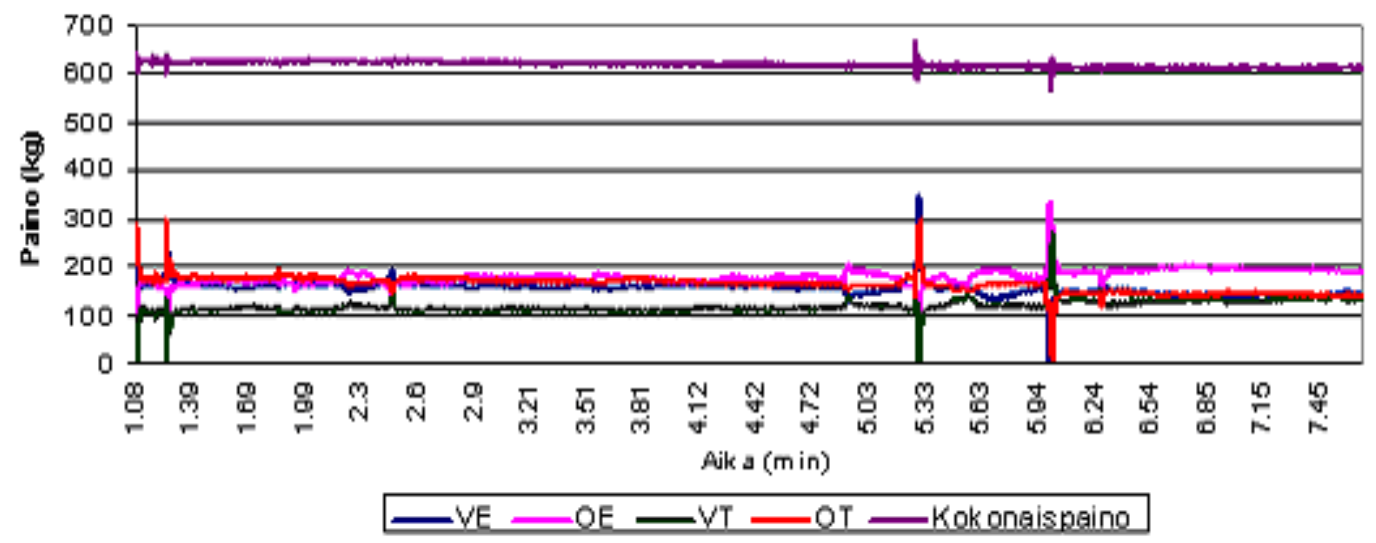

Kuva 2. Yhden lypsyn aikaiset jalkapainot. Potkut näkyvät piikkeinä datassa.

Tiedot tallennettiin tietokantaan lehmäkohtaisesti. Ohjelmassa oleva jalkavikojen etsintäehto vertasi jokaisen lypsyn päätyttyä lehmän jalkapainoja viiden edellisen päivän jalkapainoihin. Jos lehmä kevensi jatkuvasti jotakin jalkaa niin ohjelma antoi ilmoituksen mahdollisesta jalkaviasta.

Kerätty mittausdata ladattiin mittauskoneelta etäkäytöllä verkon välityksellä ja analysoitiin MATLABohjelmistolla. Lisäksi mittausohjelmasta kehitettiin lehmän tunnistava ja reaaliaikaiseen seurantaan paremmin soveltuva. Lehmille suoritettiin tutkimuksen kestäessä noin kerran kuussa toiminnallinen sorkkahoito. Sorkkahoidon yhteydessä eläinlääkäri suoritti myös sorkkaterveyden tarkastuksen ja tarkkaili lehmien käyntiä. Järjestelmällä kerättiin punnitustuloksia 71 lehmästä yli 10000 kappaletta. 
Lehmien jalkaterveys tarkastettiin noin kuukauden välein ja tutkimuksen aikana löytyi jalkavikoja yhteensä 12 lehmältä. Kaikki havaitut jalkaviat olivat lehmien takajaloissa.

\section{Tulokset}

Kuvassa 3 näkyy yhden lehmän jalkapainojen muutos sorkkavian kehittyessä. Lehmä 289 oli terve ja paino jakautui jaloille tasaisesti aikavälillä 18.6-17.9. Vaaka hajosi 17.9 ja kun se saatiin takaisin toimintaan 19.10 lehmä kevensi selvästi oikeaa takajalkaansa. Lehmän jalkaterveys tarkastettiin 3.11 sorkkahoidon yhteydessä, jolloin havaittiin valkoviivan repeämä ja oikean takajalan ulkosorkassa. Samasta sorkasta oli myös antura irti. Sorkkahoidon jälkeen lehmän paino on jakautunut tasaisesti molemmille jaloille.
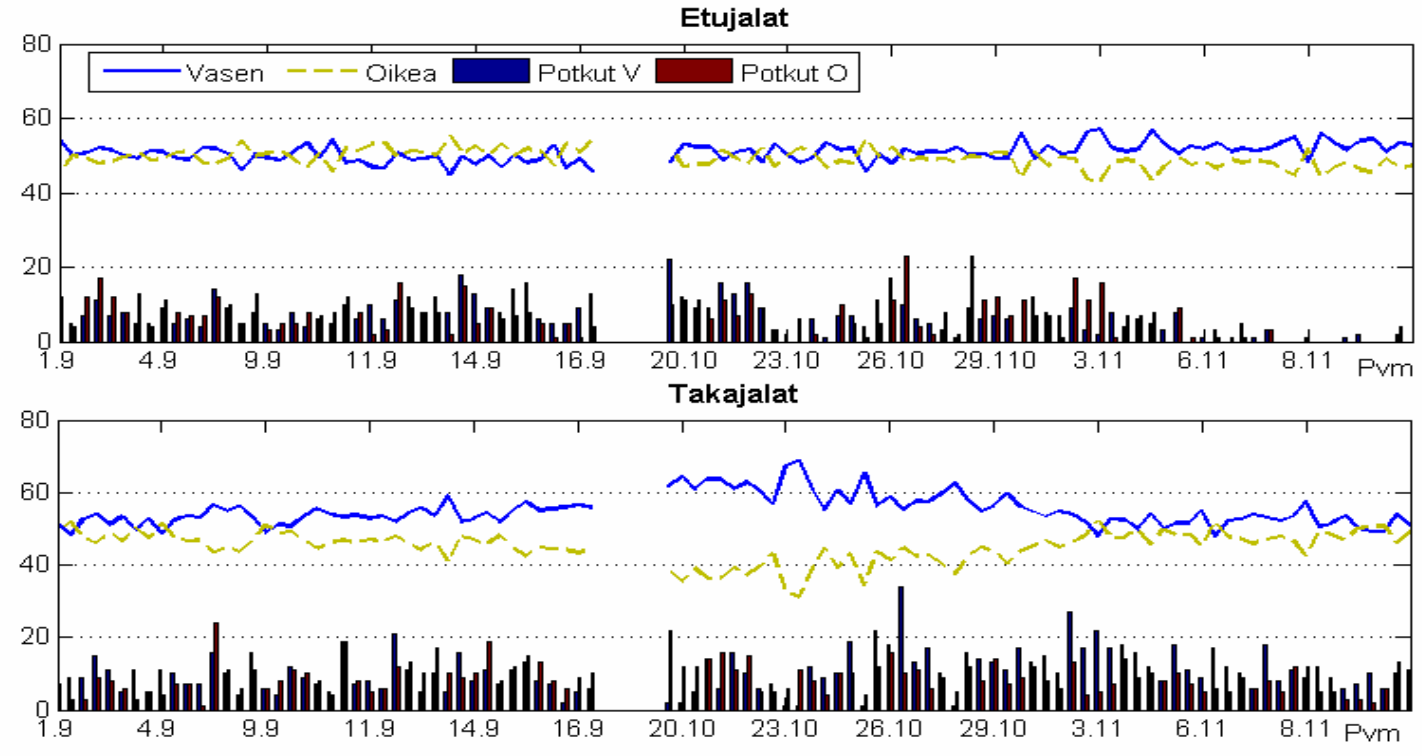

Kuva 3. Lehmän 289 etujalkojen osuus etujalkojen yhteispainosta, takajalkojen osuus takajalkojen yhteispainosta ja potkut.

Sorkkasairaudet ja muut jalkaviat näkyivät punnitustuloksissa kipeän jalan keventämisenä ja potkujen määrän kasvuna. Taulukossa 1 ja Kuvassa 4 on verrattu sorkkasairaiden lehmien keskimääräisiä takajalkojen painoja ja potkuja yhdellä lypsykerralla terveisiin lehmiin. Terveiden lehmien keskiarvot on laskettu kaikilta Elokuussa 2004 vähintään 10 kertaa vaa'alla käyneistä terveiksi todetuista lehmistä. Sairaiden lehmien keskiarvot on laskettu 7 jalkavian toteamista edeltävältä päivältä. Taulukossa verratut osuudet ovat jalkojen paino-osuuksia takajalkojen yhteenlasketusta painosta.

Taulukko 1. Terveiden ja sairaiden lehmien takajalkojen paino-osuus takajalkojen yhteispainosta (\%) ja potkut. Virheraja on \pm keskiarvon keskivirhe. (VT= Vasen takajalka, OT= oikea takajalka, MT=molemmat takajalat)

\begin{tabular}{lllll}
\hline & Osuus VT & Osuus OT & Potkut VT & Potkut OT \\
\hline Terveet $(\mathrm{n}=48)$ & $48,1 \pm 0,6$ & $51,9 \pm 0,6$ & $7,1 \pm 1,1$ & $4,6 \pm 0,5$ \\
Vika VT $(\mathrm{n}=5)$ & $40,3 \pm 2,4$ & $59,7 \pm 2,4$ & $21,3 \pm 11,1$ & $2,5 \pm 1,5$ \\
Vika OT $(\mathrm{n}=3)$ & $63,1 \pm 2,6$ & $36,9 \pm 2,6$ & $4,2 \pm 3,5$ & $17,5 \pm 11,3$ \\
Vika MT $(\mathrm{n}=4)$ & $40,6 \pm 0,6$ & $59,4 \pm 0,6$ & $9,3 \pm 2,8$ & $1,6 \pm 0,7$ \\
\hline
\end{tabular}

Terveet lehmät ovat seisseet keskimäärin paino melko tasaisesti oikealla ja vasemmalla jalalla, mutta toisen takajaloistaan satuttaneet lehmät ovat laskeneet kipeälle jalalle huomattavasti tervettä jalkaa vähemmän painoa. Ne lehmät joilla on ollut sorkkasairaus molemmissa takajaloissa ovat keventäneet vasenta takajalkaansa. (Taulukko 1, Kuva 4) Jalkavika on lisännyt osalla lehmistä kipeän jalan nostelua (=potkuja). Takajalkojen potkujen jakautumisesta terveillä ja sairailla lehmillä nähdään, että 
suuri potkujen määrä on melko varma merkki jalkaviasta. Kaikki jalkaviat eivät kuitenkaan aiheuta potkujen lisääntymistä.

Myös osa elokuussa terveiksi todetuista lehmistä laski toiselle takasorkalle selvästi vastakkaista sorkkaa vähemmän painoa. Terveiden ja sairaiden lehmien vasemman jalan painon keskimääräisestä jakaumasta (Kuva 4) nähdään, että 4 tervettä on luokissa 36-42\% ja yksi luokassa $64 \%$ :a. Toisaalta yksi vasemmasta takasorkastaan sairas lehmä on terveiden yleisimmässä luokassa $48 \%$.

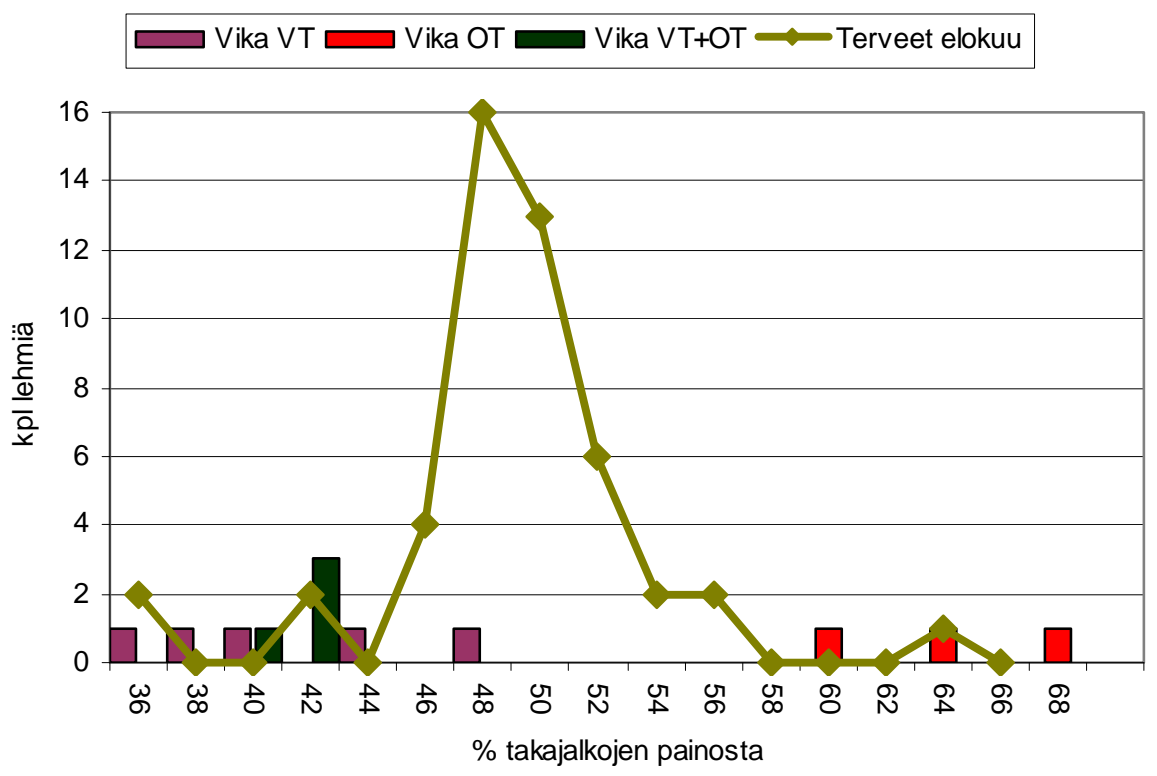

Kuva 4. Terveiden ja jalkasairaiden lehmien vasemman takajalan paino-osuuden jakauma.

\section{Tulosten tarkastelu}

Lähes kaikki lehmillä esiintyneet kliinisesti merkittävät sorkkaviat ja loukkaantumisesta johtuva ontuminen pystyttiin havaitsemaan nelivaakajärjestelmällä. Sairaiden lehmien kipeä jalka pystyttiin erottamaan merkittävän keventämisen ja joissain tapauksissa lisääntyneen potkimisen avulla. Myös osa terveistä lehmistä keventää toista takajalkaansa ja niitä ei pystytty erottamaan vaakatiedoista kaikissa tapauksissa sairaista lehmistä. Kaikki tutkimuksen aikana löytyneet jalkaviat olivat takajaloissa, joten etujaloissa olevien vikojen esiintymistä ei voitu tarkastella. Lehmät laskivat keskimäärin vasemmalle takajalalle hieman vähemmän painoa kuin oikealle. Tämä johtuu todennäköisesti siitä, että osa lehmistä nojaa oikealle puolelle robotin runkoon.

Parhaiten vaa'alla erottuivat ne lehmät joilla oli vikaa ainoastaan toisessa takajalassa. Selvästi toista jalkaansa ontuvat lehmät kevensivät kipeää jalkaa selvästi ja usein myös potkujen määrä oli huomattavasti suurempi kuin terveillä lehmillä. Eniten potkuja havaittiin selvimmin ontuvilla lehmillä. Keventämistä ja potkimista voidaankin pitää lähes varmana ontumisen merkkinä. Toisaalta kaikki keventävät ja potkivat lehmät ontuivat niin selvästi, että jalkavika oli helppo havaita myös silmämääräisesti. Jos lehmällä oli vikaa molemmissa jaloissa, niin se ei erottunut kaikissa tapauksissa yhtä selvästi kuin vain yhdessä jalassa olleet viat.

Lehmien erilainen käyttäytyminen vaikeuttaa yhteisten kriteerien löytämistä ja aiheuttaa vääriä hälytyksiä. Väärien hälytysten määrään voidaan vaikuttaa säätämällä ohjelman hälytysherkkyyttä. Kun raja säädetään vähemmän herkäksi niin jalkaviat havaitaan vasta niiden aiheuttaessa selvää ontumista eli lievät sorkkaviat jäävät havaitsematta, mutta samalla ohjelman antamien väärien hälytysten määrä laskee. Järjestelmällä pystytään erottamaan lievemmät vaivat vakavasta ontumisesta, mutta esimerkiksi eri sorkkasairauksien erottaminen toisistaan ei ainakaan tämän hetkisen aineiston perusteella onnistu. 


\section{Johtopäätökset}

Lehmän jalkapainojen yksilöllisellä seurannalla pystytään seuraamaan eläimen jalkaterveyttä. Nelivaakajärjestelmä tarjoaa mahdollisuuden automaattiseen terveyden seurantaan tilatasolla. Järjestelmää ohjaava ohjelma antaa automaattisia hälytyksiä mahdollisista ongelmista. Hälytysten avulla karjanhoitaja voi tarkastaa lehmän kunnon ja kutsua tarvittaessa eläinlääkärin. Kaikki tutkimuksen aikana havaitut ontumistapaukset pystyttiin havaitsemaan järjestelmällä, mutta se antaa edelleen myös melko paljon vääriä hälytyksiä.

\section{Kirjallisuus}

Frost, A. R., Schofield, C. P., Beaulah, S. A., Mottram, T. T., Lines, J. A. \& Wathes, C.M. 1997. A review of livestock monitoring and the need for integrated systems. Computers and Electronics in Agriculture 17:139159.

Hillerton, J., Dearing, J., Dale, J., Poelarends, J., Neijenhuis, F., Sampimon, O., Miltenburg, J. \& Fossing, C. 2004. Impact of Automatic Milking on Animal Health. Automatic Milking. Wageningen Academic Publishers. Wageningen. s. 125-134.

Juarez, S. T., Robinson, P. H., DePeters, E. J. \& Price, E. O. 2003. Impact of lameness on behaviour and productivity of lactating Holstein cows. Applied Animal Behaviour Science 83: 1-14.

Klaas, I. C., Rousing, T., Fossing, C., Hindhede, J. \& Sörensen, J. T. 2003. Is lameness a welfare problem in dairy farms with automatic milking systems? Animal Welfare 12(4): 599-603.

Pastell, M., Takko, H., Gröhn, H., Hautala, M., Poikalainen, V., Praks, J., Veermäe, I. Kujala, M. \& Ahokas J. Assessing Cow's Welfare: Weighing the Cow in a Milking Robot. Biosystems Engineering. (In press)

Takko, H. 2004. Nelivaakajärjestelmän toimivuus sorkkasairauksien havainnoinnissa. Pro gradu-tutkielma, Maa- ja kotitalousteknologian laitos. $57 \mathrm{~s}$.

Vermunt, J. 2004. Herd Lameness- A Review, Major Causal Factors, and Guidelines for Prevention and Control. Proceedings of $13^{\text {th }}$ International Symposium and $5^{\text {th }}$ Conference on Lameness in Ruminants. 